\title{
FORRAGEAMENTO DA ABELHA AFRICANIZADA NA FLORADA DA BRACATINGA
}

\author{
Adhemar Pegoraro, Anselmo Chaves Neto, Sonia Maria Noemberg Lazzari, \\ Bárbara Karolina Ratier da Silva
}

Universidade Federal do Paraná

Endereço para correspondência: Adhemar Pegoraro: apegoraro@ufpr.br

\begin{abstract}
RESUMO: O experimento foi desenvolvido no Município de Mandirituba, Paraná, com o objetivo de avaliar o forrageamento das operárias de Apis mellifera L. em inflorescências de Bracatinga. As operárias foram coletadas com rede entomológica, entre $10 \mathrm{~h}$ e $16 \mathrm{~h}$, em oito dias ensolarados, no período de 5 a 28 de agosto de 2001. As abelhas capturadas foram imediatamente anestesiadas para que o conteúdo da vesícula melífera fosse avaliado com refratômetro manual para medir a concentração de sólidos solúveis totais (açúcares) no néctar. Em média, $27,02 \pm 9,88 \%$ das operárias forrageavam néctar e pólen ao mesmo tempo, com o pico de abelhas portando néctar às $15 \mathrm{~h}$ e de pólen às $13 \mathrm{~h}$. Diferenças estatísticas foram observadas na concentração de açúcares no néctar entre as horas do dia, que variou de $18,5 \%$ a $36,8 \%$, com o pico às $13 \mathrm{~h}$. A concentração de açúcares no néctar apresentou uma correlação positiva direta e moderada com a temperatura; foi inversamente correlacionada com a umidade relativa no ar; e não apresentou correlação significativa com a luminosidade.
\end{abstract}

Palavras-chave: Apis mellifera, Mimosa scabrella, néctar, pólen, comportamento forrageiro.

\section{FORAGING OF THE AFRICANIZED HONEYBEE ON BRACATINGA FLOWERS}

ABSTRACT: This experiment was conducted in Municipality of Mandirituba, Paraná, to assess the foraging behavior of Apis mellifera $\mathrm{L}$. workers on Bracatinga flowers. The worker bees were collected using an insect net from 10h to 16h, during eight sunny days, from August 5 to 28, 2001. The bees were immediately anesthetized and the crop content was evaluated using a manual refractometer to measure the total soluble sugar in the nectar. On average $27.02 \pm 9.88 \%$ of the bees presented nectar and pollen simultaneously, with the peak of bees carrying nectar at 3 p.m. and pollen at 1 p.m. Statistical differences were observed on nectar sugar concentration amongst hours of the day varying from $18.5 \%$ to $36.8 \%$, with the peak at 1 p.m. The sugar concentration in the nectar was moderate and directly correlated to temperature; inversely correlated to relative humidity; and was not correlated to luminosity.

Key Words: Apis mellifera, Mimosa scabrella, nectar, pollen, foraging behavior. 


\section{INTRODUÇÃO}

As operárias de Apis mellifera L. (Hymenoptera: Apidae) podem forragear néctar, pólen ou néctar mais pólen simultaneamente em uma mesma espécie vegetal Fewell e Winston (1992). Nas colônias de A. mellifera, o néctar é transformado em mel e armazenado, para depois ser consumido como fonte de energia, enquanto o pólen é utilizado como fonte de proteína, lipídios e vitaminas para desenvolver a cria (Camazine, 1993). As operárias forrageiras da $A$. mellifera comparam o volume do néctar e a concentração de açúcares do néctar das flores e visitam com maior frequência as espécies que oferecem maiores recompensas (Goulson, 1994).

A Bracatinga, Mimosa scabrella Bentham (Mimosaceae), é uma espécie nativa do sul do Brasil, pioneira, arbórea, de ocorrências em áreas de formações secundárias da Floresta Ombrófila Mista Montana (Floresta com Araucária), comum em capoeiras e capoeirões (Mazza et al., 2000; Martins e Orth, 2004). Caracteriza-se por apresentar crescimento rápido. É adaptada em solos de baixa fertilidade e sem déficit hídrico (Carpanezzi e Carvalho, 1988).

A madeira de Bracatinga fornece lenha e carvão de excelente qualidade (Silva et al., 1983), pode ser usada como vigamentos na construção civil, caixoteria, compensados, laminados e aglomerados (Lorenzi, 1992). A planta pode ser utilizada na recuperação florestal e de solos degradados (Carpanezzi e Carvalho, 1997) e como recurso para a apicultura (Mazuchowski, 1990). A Bracatinga fornece néctar e pólen durante 0 inverno $e$ isso é importante para a apicultura, pois nessa época o alimento para as abelhas é escasso na natureza e quando não há florada da Bracatinga é necessário administrar alimentação artificial ou cultivar Nabo forrageiro (Raphanus sativus). Essa florada prepara as colônias com aumento da população para utilizar a florada principal da primavera (Sommer, 1972). Em Bracatingal com espaçamento de $2 \times 3 \mathrm{~m}$ e sete anos de idade estimou-se produção média de $120 \mathrm{~kg}$ de mel por hectare (Pegoraro e Carpanezzi, 1995).

No Bioma Floresta Ombrófila Mista (Floresta com Araucária) no Sul do Brasil existem quatro floradas nativas utilizadas pela apicultura: Bracatinga, capoeira com espécies principalmente do gênero: Vernonia, Baccharis e Eupatorium e espécies das famílias Poaceae, Melastomataceae e outras inclusive Pteridium aquilinum (Pteridaceae). As associações arbóreas desta fase são complexas, mas basicamente constituídas por espécies pioneiras, além de espécies secundárias iniciais aparecerem em profusão com Schinus terebenthifolius (Anacardiaceae), Ilex paraguaiensis (Aquifoleaceae), Ocotea puberula (Lauraceae), Prunus brasiliensis; (Rosaceae), Rapanea ferruginea (Myrsinaceae) entre outras (Pegoraro, 2003).

Capoeirão: constituído por espécies arbóreas que atingem 10 a 12 metros de altura, cuja composição se assemelha fisionomicamente à floresta primária. Nesse caso, aparece Araucária angustifólia emergindo no dossel, além da profusão das Lauraceas, Sapindacea, Meliacea, Aguifoliaceae, Flacoutiaceae entre outras. Constitui-se, a partir daí, a floresta secundária, esta fase difere das formações primárias, sobretudo pelo porte das espécies, já que a composição florística é semelhante (Pegoraro, 2003).

Os objetivos deste trabalho foram: avaliar a concentração de sólidos solúveis (açúcares) no néctar da Bracatinga; avaliar o percentual médio de operárias sobre as inflorescências 
dessas plantas, que portavam néctar, pólen, ambos (néctar mais pólen) e que não portavam alimento; correlacionar a concentração de sólidos solúveis totais (açúcares) no néctar à temperatura atmosférica, à umidade relativa no ar e à luminosidade.

\section{MATERIAL E MÉTODOS}

O estudo foi conduzido em um apiário constituído por 12 colônias de abelhas africanizadas, localizado no Município de Mandirituba, PR (longitude

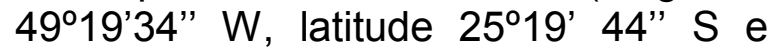
altitude de $840 \mathrm{~m}$ ).

As abelhas foram coletadas com rede entomológica em quatro árvores floridas de Bracatinga situadas a aproximadamente $200 \mathrm{~m}$ do apiário, nos primeiros cinco minutos de cada hora do dia, em oito dias, no período de 5 a 28 de agosto de 2001.

No experimento, os horários correspondem aos níveis (tratamentos) do fator principal (hora da coleta) e o seu número é $a=7$. A porcentagem média de operárias que portavam néctar, pólen e néctar mais pólen, e a concentração de sólidos solúveis totais (açúcares) no néctar da vesícula melífera das operárias, correspondem às quatro variáveis-resposta $Y_{p}, p=1,2$, 3, 4. Portanto, têm-se quatro experimentos, em delineamento do tipo blocos casualizados, considerando os dias como blocos (fator secundário) da amostragem. Assim, tem-se o número de níveis desse fator igual a $b=8$.

As unidades experimentais são as operárias forrageiras de $A$. mellifera. Fixou-se um número de 15 operárias capturadas sobre as inflorescências de Bracatinga, coletadas e avaliadas de hora em hora, no período em que as inflorescências de Bracatinga disponibilizam alimento. As operárias forrageiras foram coletadas, imobilizadas em tubo de ensaio com algodão e acetato de etila; em seguida, submetidas às seguintes observações: presença ou ausência de pólen nas corbículas, presença ou ausência de néctar na vesícula melífera, de acordo com o procedimento de Juliano (1972). Nas operárias que portavam exclusivamente néctar foram determinadas as concentrações de sólidos solúveis totais (açúcares) do mesmo, com o auxílio de dois refratômetros de mão. $\mathrm{O}$ primeiro com capacidade de medir de 0 a 35 graus brix; o segundo com capacidade de medir 30 a 60 graus brix e com variação máxima de $1 \%$ a $20^{\circ} \mathrm{C}$, conforme Pegoraro (2003). Em seguida, foram calculadas as percentagens médias da população de abelhas que portavam néctar, pólen ou ambos (néctar mais pólen) e operárias que não portavam alimento.

O modelo linear ajustado aos dados de cada um dos quatro experimentos foi:

$$
y_{i j k}=\mu+\alpha_{i}+\beta_{j}+(\alpha \beta)_{i j}+\varepsilon_{i j k}
$$

com, $\mathrm{i}=1,2, \ldots, 7$ (horas); $\mathrm{j}=1,2, \ldots, 8$ (dias) e k =1,2, .., 15 (operária).

O tamanho da amostra a ser observada, $n$, foi dimensionada partindo-se da estimativa do percentual de abelhas que não estavam forrageando. Seja $\theta$ esse percentual a ser estimado e como o tamanho da população de operárias forrageiras é desconhecido, assume-se que essa população seja infinita. $O$ valor de $\square_{0}$ foi determinado experimentalmente com os dados de um dia de trabalho. De forma que $\square_{0}$ foi estimado em $0,25=25 \%$, com as informações do primeiro dia. Então, tem-se o dimensionamento final para $n$, dado por:

$$
\mathrm{n} \geq \frac{z^{2} \mathbf{Q}_{0}\left(1-\theta_{0}\right)}{d^{2}} \operatorname{com} \cdot \theta_{0}=0,25
$$


Precisão (margem de erro) igual a $\mathrm{d}=$ $0,03=3 \%$ e um nível de confiança igual a $1-\square=95 \%$ que corresponde a um escore padronizado de $z=1,96$. Portanto, tem-se $\mathrm{n}=800,33$. No desenvolvimento do experimento completo conseguiu-se um tamanho de amostra de 840 abelhas correspondendo a 8 dias $\times 7$ horas $\times 15$ operárias que supera 0 tamanho necessário. Evidentemente, com esse $n$ maior tem-se uma precisão melhor, ou seja, $d=0,029=2,9 \%$.

Construiu-se a matriz de correlação entre as variáveis: concentração de sólidos solúveis totais (açúcares) no néctar e as variáveis ambientais: temperatura, umidade relativa atmosférica e luminosidade, conforme Pegoraro (2003).

A temperatura, a umidade relativa atmosférica e a luminosidade foram verificadas nos primeiros cinco minutos de hora em hora, das $10 \mathrm{~h}$ as 16h, durante oito dias, com auxílio de um termo higrômetro manual com variação máxima nas temperaturas de $\pm 1^{\circ} \mathrm{C}$, para temperatura entre -10 e $60^{\circ} \mathrm{C}$ e umidade relativa no ar entre 25 e 95\% com variação máxima de $5 \%$. Esses dados foram coletados ao nível do solo, a campo, conforme descrito por Nicolson (1994). A luminosidade foi obtida com luxímetro, no campo, e a sua unidade foi quantificada em $\mathrm{KW}^{-1} / \mathrm{m}^{2}$ a pleno sol, conforme Funari et al. (1997).

Em função da natureza dos dados, aplicou-se a Análise de Variância Clássica (ANOVA) para testar a hipótese nula da não existência de diferença estatisticamente significativa entre os horários. Fixou-se um nível de significância de 5\%.

\section{RESULTADOS}

A hipótese de igualdade entre as médias na variável concentração de sólidos solúveis totais (açúcares) no néctar da Bracatinga foi rejeitada porque existiu diferença estatisticamente significativa entre as horas do dia $p=$ 0,0001. A média diária total da concentração de açúcares no néctar da Bracatinga coletado na vesícula melífera da $A$. mellifera foi de $30,03 \%$. Já ás $10 \mathrm{~h}$ a concentração média de sólidos solúveis foi de $18,50 \%$, a mais baixa em relação aos demais horários (Tabela 1 ).

Tabela 1 - Porcentagem média de sólidos solúveis totais (açúcares) no néctar coletado na vesícula melífera de operárias forrageiras sobre as inflorescências da Bracatinga e porcentagem de operárias forrageiras de $A$. mellifera que portavam néctar, pólen e ambos.

\begin{tabular}{lccccccccc}
\hline Horas & 10 & 11 & 12 & 13 & 14 & 15 & 16 & Média\% & P \\
S. S. T\%* & 18,50 & 25,34 & 31,98 & 36,8 & 35,10 & 33,23 & 29,27 & 30,03 & 0,0001 \\
Néctar\%* & 23,33 & 24,16 & 27,49 & 22,49 & 29,16 & 36,66 & 33,38 & 28,03 & 0,007 \\
Pólen\%* & 19,16 & 25,85 & 23,32 & 22,11 & 25,81 & 14,16 & 11,65 & 21,30 & 0,001 \\
Ambos\%* & 25,83 & 24,16 & 29,99 & 29,16 & 24,99 & 13,33 & 17,49 & 27,02 & 0,001 \\
S. A & 34,68 & 25,83 & 19,20 & 19,24 & 20,04 & 35,85 & 37,48 & 23,65 & 0,002 \\
\hline
\end{tabular}

*Diferença estatisticamente significativa, $\mathrm{P}$. Valor de probabilidade

S. S. T = Sólidos solúveis totais (açúcares) no néctar em ${ }^{\circ}$ brix; ambos= néctar mais pólen.

S. A. Sem alimento.

O percentual médio de operárias que portavam néctar proveniente das inflorescências da Bracatinga foi de $28,03 \pm 9,23 \%$, com porcentagens mínima e máxima, respectivamente de $22,49 \%$ às $13 \mathrm{~h}$ e $36,66 \%$ às $15 \mathrm{~h}$ (Tabela 1). Para esta variável foram encontradas diferenças significativas entre as horas do dia (tratamento) demonstrado através do $p=0,007$ (Tabela 1).

Na tabela 1, a variável aleatória percentagem de pólen coletado pelas operárias forrageiras (operárias forrageiras coletando pólen) nas inflorescências de Bracatinga também foram encontradas diferenças significativas entre as horas do dia (tratamento) demonstrado através do $\mathrm{p}$ $=0,001$ (Tabela 1). Com média 21,30 \pm $9,11 \%$ e com pico entre $13 \mathrm{~h}$.

Em média, 27,02 $\pm 9,88 \%$ das operárias forrageiras que estavam 
Forrageamento Da Abelha Africanizada Na Florada Da Bracatinga

forrageando

alimento

nas

inflorescências de Bracatinga portavam néctar e pólen simultaneamente (Tabela 1). Foram encontradas diferenças significativas entre as horas do dia (tratamento) demonstrado através do $p$ $=0,001$.

A percentagem de operárias forrageiras que estavam sobre as inflorescências da Bracatinga, mas não portavam recursos alimentares no momento da coleta das amostras foi de $23,65 \%$. Foram encontradas diferenças significativas entre as horas do dia (tratamento) demonstrado através do $p$ $=0,002$.

A correlação entre a concentração de sólidos solúveis (açúcares) no néctar foi significativamente direta e moderada com a temperatura; direta e fraca com a luminosidade e inversa e moderada com a umidade relativa no ar (Tabela 2 ).

Tabela 2 - Matriz de correlação de Spearmam entre as variáveis: porcentagem de açúcares no néctar coletado nas operárias forrageiras sobre as inflorescência de Bracatinga, temperatura, umidade relativa do ar e luminosidade.

\begin{tabular}{c|ccc}
\hline $\begin{array}{c}\text { Fatores } \\
\text { Ambientais }\end{array}$ & S.S.T & $\begin{array}{c}\text { Temperatura } \\
\left({ }^{\circ} \mathrm{C}\right)\end{array}$ & UR $(\%)^{2}$ \\
\hline Temperatura & 0,6329 & & \\
& $(56)$ & & \\
Umidade & $0,0001^{*}$ & & \\
relativa do ar & $-0,6898$ & $-0,7617$ & \\
& $(56)$ & $(56)$ & \\
Luminosidade & $0,0001^{*}$ & $0,0001^{*}$ & \\
& 0,3044 & 0,2187 & $-0,4641$ \\
& $(56)$ & $(56)$ & $(0,56)$ \\
& $0,0226^{*}$ & $0,1053^{*}$ & $0,0003^{*}$ \\
\hline
\end{tabular}

S.S.T = Sólidos solúveis totais (açúcares) no néctar em ${ }^{\circ}$ brix;

${ }^{2} \mathrm{UR}=$ Umidade relativa do ar;

*Diferença estatisticamente significativa em nível de $5 \%$

\section{DISCUSSÃO}

Diferenças significativas existiram nas médias das concentrações de sólidos solúveis (açúcares) do néctar de inflorescências da Bracatinga $p=$ 0,0001 . Às $10 \mathrm{~h}$ ocorreu a menor concentração de sólidos solúveis (açúcares) no néctar devido a baixa temperatura e alta umidade relativa no ar conforme (Szabo, 1980; Pegoraro, 2003; Pegoraro e Chaves Neto, 2005). Quando a concentração de sólidos solúveis (açúcares) no néctar for baixa, como as $10 \mathrm{~h}$ na tabela 1 , exige mais trabalho para as abelhas transformarem o néctar em mel (Pegoraro e Carpanezzi, 1995). Essas variáveis se comportaram de forma similar em Frutode-pombo (Rhamnus sphaerosperma) Rhamnaceae (Pegoraro, 2003) e em Flor-das-almas (Senecio brasiliensis) (Pegoraro e Chaves Neto, 2005).

$\mathrm{Na}$ Bracatinga o percentual médio de operárias forrageiras que portavam néctar foi de $28,03 \%$ (tabela 1 ).

Martins e Orth (2004) citam que a Bracatinga disponibiliza néctar e pólen no final do inverno. Operárias forrageiras capturadas sobre as inflorescência da Bracatinga que portavam alimento foram em média néctar $28,03 \%$, pólen $21,30 \%$, ambos $27,02 \%$ e nada 23,65\% (Tabela 1 ).

Em Fruto-de-pombo $36,62 \%$ das operárias forrageiras portavam néctar, $12,35 \%$ portavam pólen, 14,45\% portavam ambos e $36,62 \%$ não portavam alimento (Pegoraro, 2003) e os apicultores a consideram como planta produtora de mel.

Em flor-das-almas (Senecio brasiliensis) 30,07\% das operárias forrageiras portavam néctar, 21,06\% portavam pólen, $20,19 \%$ portavam simultaneamente néctar e pólen e $28,68 \%$ não portavam alimento (Pegoraro e Chaves Neto, 2005). Os apicultores produtores de pólen consideram essa planta boa produtora de pólen. Em Jerivá (Syagrus romanzofiana) $5,07 \%$ das operárias forrageiras portavam néctar, 29,68\% portavam pólen , 52,61\% portavam ambos (néctar mais pólen) e 12,64\% não portavam alimento (Oliveira e Pegoraro dados não publicados), 
acreditamos que o Jerivá possa ser considerado uma planta polinífera.

O ótimo desenvolvimento das colônias de abelhas africanizadas durante o inverno na área de ocorrência natural da Bracatinga, Sul do Brasil, aonde sua florada é predominante sugere que seu pólen é de excelente valor nutritivo. Nessa florada os apicultores podem estimular as colônias a se desenvolver sem alimentação artificial para utilizarem com eficiência a florada da Bracatinga. Durante a florada de Bracatinga é possível, ainda, renovar aproximadamente $40 \%$ dos favos das colméias (Pegoraro e Silva, 1996), colher mel, e se for do interesse do apicultor durante 0 mês de agosto coletar pólen apícola.

A existência de operárias que portavam pólen, entre as horas do dia, foi diferente estatisticamente significativa $p=0,001$. A percentagem média de operárias que portavam pólen foi de $21,30 \pm 9,11 \%$, sendo que a maior porcentagem de operárias que portavam pólen ocorreu entre as $11 \mathrm{~h}$ e $14 \mathrm{~h}$ (Tabela 1), caracterizado como 0 período mais propício para a coleta de pólen. Picos na disponibilidade de pólen também foram observados em kiwi (Actinidia deliciosa) Goodwin (1995). A quantidade de pólen que as operárias forrageiras coletam pode ser influenciada pela necessidade da colônia ou característica da espécie vegetal (Beauchamp, 1992). É importante conhecer o período que as plantas apícolas disponibilizam alimento para as abelhas para o apicultor programar os horários de coleta de pólen. Moura e Pegoraro (2006) observaram que o início e o final da entrada de pólen de Bracatinga nas colônias de abelhas africanizadas ocorreu em média entre às 09h:46min e 14h:26min.

Nas operárias que forragearam néctar mais pólen simultaneamente, existiu diferença estatisticamente significativa $(p=0,001)$ entre as horas do dia (tratamento), com pico entre $12 \mathrm{e}$ 13h, coincidindo com o pico de forrageamento de pólen que foi ás $13 \mathrm{~h}$ (tabela 1), sendo que a disponibilidade de néctar e pólen neste horário pode ser característica própria da Bracatinga, mas a decisão de coletar pólen pelas operárias forrageiras de $A$. mellifera também depende do número de larvas, quantidade de pólen estocado na colônia, genótipo das abelhas e disponibilidade de alimento na natureza (Pankiw et al., 1998).

$\mathrm{Na}$ tabela 1 observa-se que a partir das $15 \mathrm{~h}$ houve redução nas percentagens de operárias que forrageavam pólen e néctar mais pólen.

A percentagem média de operárias forrageiras que estavam sobre as inflorescências da Bracatinga buscando alimento, mas que no momento da coleta das amostras ainda não o portavam foi de $23,65 \%$ com variação entre as horas do dia (tabela 1). Esse valor é inferior aos observados em Fruto-de-pombo com média de $36,6 \%$ (Pegoraro, 2003) e Flor-dasalmas 28,68\% (Pegoraro e Chaves Neto, 2005), provavelmente porque a Bracatinga, mesmo florescendo no inverno, disponibiliza mais alimento do que as espécies acima citadas.

A presença de operárias forrageiras sem alimento sobre as flores da Bracatinga ocorreu porque elas ainda não haviam coletado o alimento no momento em que foram amostradas. A partir das $15 \mathrm{~h}$ houve aumento da percentagem de operárias sem alimento (tabela 1).

Observa-se que os horários de menor percentual de operárias forrageiras sem alimento e 0 mais favorável à atividade das operárias forrageiras ocorreu entre $11 \mathrm{~h}$ às $14 \mathrm{~h}$ (tabela 1). As condições ambientais mais desfavoráveis: temperatura baixa e umidade relativa no ar alta ocorram ás 
10h, 15h e 16h (tabela 1) e nesse período a disponibilidade de alimento, freqüência de operárias forrageiras e consequentemente a recompensa foram as menores do dia em concordância com Szabo (1980); Goulson (1994); Nicolson (1998), Pegoraro (2003); Pegoraro e Chaves Neto (2005).

A correlação entre as variáveis: temperatura atmosférica e concentração de sólidos solúveis totais (açúcares) no néctar coletado nas operárias sobre as inflorescências de Bracatinga foram diretas, moderadas e significativas (Tabela 2), corroborando com os dados obtidos por Szabo (1980); Goulson (1994); Nicolson (1994, 1998) Pegoraro (2003) e Pegoraro e Chaves Neto (2005).

$\mathrm{Na}$ Bracatinga a correlação entre a concentração de açúcares no néctar e a umidade relativa no ar foi inversa, moderada e significativa (Tabela 2). Essa tendência também foi observada em Eucalipto sp, por Nicolson (1994). O mesmo ocorreu com Fruto-de-pombo por Pegoraro (2003) e Flor-das-almas (Pegoraro e Chaves Neto, 2005).

Szabo (1980) observou que as variáveis temperatura e luminosidade apresentam comportamento similar com relação à concentração de sólidos solúveis (açúcares) no néctar. Esses fatores foram os mais importantes na atividade das operárias forrageiras e no ganho de peso das colônias de $A$. mellifera.

$\mathrm{Na}$ tabela 2 observa-se que as correlações foram respectivamente de $r$ $=0,6329$ e $r=0,0226$ para essas variáveis e consideram a luminosidade com pouca influência na concentração de sólidos solúveis (açúcares) no néctar da Bracatinga.

A influência não significativa da luminosidade na concentração de sólidos solúveis (açúcares) no néctar da Bracatinga pode ser atribuída à metodologia de coleta das amostras, pois nos primeiros cinco minutos de cada hora eram coletadas as amostras e as vezes nesse momento as nuvens passageiras diminuíam a intensidade luminosa $e$ isso pode ter alterado os resultados. Talvez essa metodologia tenha que ser adaptada.

\section{CONCLUSÃO}

A concentração de sólidos solúveis totais (açúcares) durante o dia no néctar da Bracatinga segue a tendências de outras espécies apícolas.

Em função dos percentuais médios de operárias que portavam néctar, pólen, ambos e sem alimento (nada) a Bracatinga pode ser considerada nectaro-polinífera.

O horário mais adequado para coletar pólen com coletor em uso não continuo ocorreu entre $11 \mathrm{~h}$ e $14 \mathrm{~h}$.

Os fatores abióticos: temperatura associada á umidade relativa no ar, podem ser considerados decisivos para determinar a concentração de sólidos solúveis (açúcares) no néctar da vesícula das operárias coletadas sobre as inflorescências da Bracatinga.

Quanto maior for a umidade relativa no ar menor será a concentração de sólidos solúveis (açúcares) no néctar da Bracatinga, dificultando 0 trabalho das abelhas transformarem o néctar em mel.

\section{REFERÊNCIAS}

BEAUCHAMP, G. Effects of energy requirements and worker mortality on colony growth and foraging in the honey bee. Behaviou Ecology Sociobiology, v.31, n.2, p. 123-132, 1992.

CAMAZINE, S. The regulation of pollen foraging by honey bee: how foragers assess the colony's need for pollen. Behavioral Ecology and Sociobiology, v. 32, n.4, p. 265-272, 1993.

CARPANEZZI, A. A.; CARVALHO, P. E. Manual técnico da Bracatinga Mimosa scabrella (Benth.). Curitiba: EMBRAPA-CNPF, 1988. 70 p. (Documento, 20). 
FEWELL, J. H.; WINSTON, M. Colony state and regulation of pollen foraging in the honey bee, (Apis mellifera L.), Behavioral Ecology and Sociobiology, v. 30, n.6, p. 387-393, 1992.

FUNARI, S. R. C.; BAUSB-VIANA, M. J.; CURI, P. R.; FUMARI, A. R. M. A estratégia de coleta de néctar das abelhas africanizadas (Apis mellifera L.), Boletim da Indústria Animal, v. 54, n. 2, p. 67-73, 1997.

GOODWIN, R. M. Afternoon declive kiwifruit pollen collection. New Zealand Journal of Crop \& Horticultural Science, v.23, n.2, p.163-171, 1995.

GOULSON, D. A. Model to predict the influence of insect flower constancy on interspecific competition between insect pollinated plants. Journal of Theoretical Biology, v.168, n. 3, p. 309-314, 1994.

MARCEAU, J.; BOLLY, R.; PERRON, J. M. The relationship between hive productivity and honeybee flight activity. Journal Apiculture Research, v. 29, n. 1, p. 35-45, 1990.

MARTINS, M.; ORTH, A. I. Bracatinga: uma espécie para produção de mel e polinização dirigida no planalto catarinense. In: CONGRESSO BRASILEIRO DE APICULTURA, $X V, 2004$, CONGRESSO BRASILEIRO DE MELIPONICULTURA, 1, 2004, Natal. Anais... Natal, 2004, CD-ROM.Trabalhos Técnicos.

MAZZA, C. A. S.; BAGGIO, A. J.; CARPANEZZI, A. A. Distribuição espacial da Bracatinga na região metropolitana de Curitiba com imagens de satélite landsat. Colombo: Embrapa Florestas, 2000. 23p. (Embrapa Florestas. Circular Técnica, 36).

MAZUCHOWSKI, J. Z. Organização da reposição florestal. Curitiba: PROJETO FAOGCP/ BRA/025/FRA., 1990. 126p. (Série Subsídios Florestais, 2).

MOURA, J.; PEGORARO, A. Produção de pólen apícola com coletor nos horários de disponibilidade de alimento no pico da florada de Bracatinga (Mimosa scabrella). Scientia Agrária, v.7, n.1-2, p. 97-100, 2006.

NICOLSON, S. W. Eucalyptus nectar: production, availability, composition and osmotic consequences for the larva of the eucalypt nectar fly, Drosophila flavohirta. SuidAfrikaanseTydskrif vir Wetenskap, v.90, n.2, p. $75-79,1994$.
NICOLSON, S. W. The importance of osmosis in nectar secretion and its consumption by insects. American Zoologist, v. 38, n. 3, p. 418-425, 1998.

PANKIW, T.; PAGE Jr.; R. E.; FRONDRK, M. K. Brood pheromone stimulates pollen foraging in honey bees (Apis mellifera). Behaviour Ecology and Sociobiology, v.44, n.3, p.193198, 1998.

PEGORARO, A.; CARPANEZZI, A. A. Avaliação do potencial melífero da Bracatinga. Revista do Setor de Ciências Agrárias, v. 14, n. 2, p. 167$172,1995$.

PEGORARO, A.; SILVA, F. C. Espécies vegetais preferidas pela Apis mellifera scutellata (Himenóptera: Apidae) em Colombo-PR. Revista do Setor de Ciências Agrárias, v. 15, n. 1, p.25-31, 1996.

PEGORARO, A.; CHAVES NETO, A. Disponibilidade de alimento coletado por operárias da abelha africanizada em função dos fatores ambientais. Scientia Agrária, v. 6, n. 12, p.35-39, 2005.

PEGORARO, A. Estudo da integração de diversos fatores no manejo de abelhas africanizadas Apis mellifera Linnaeus., 1758 (Hymenoptera: Apidae), na unidade fitogeográfica da floresta com araucária, no sul do Brasil. 2003. f 149. (Doutorado em Produção Vegetal) - Pós-Graduação em Agronomia, Universidade Federal do Paraná.

JULIANO, J. C. Identificação de espécies de interesse apícola do Rio Grande do Sul. In: CONGRESSO BRASILEIRO DE APICULTURA, II, 1972, Sete Lagoas. Anais... Sete Lagoas, 1972 , p. $85-118$

SOMMER, P. G. Observações em apiários no Estado do Paraná no período de 1942 a 1972. In: CONGRESO BRASILEIRO DE APICULTURA. II., 1972. Sete Lagoas. Anais... Sete Lagoas, 1972, p.130-132.

SZABO, T. I. Effect of weather factors on honeybee a flight activity and colony weight gain. Journal Apicultural Search, v.19, n.3, p.164171, 1980. 